\title{
PREDICTORS OF BREAST SELF-EXAMINATION UPTAKE AMONG WOMEN IN MALE' REGION, MALDIVES
}

\author{
Aishath Niyaf ${ }^{1}$, Sairah AK$^{1}$ and Mohammed A. Abdalqader ${ }^{2}$ \\ ${ }^{1}$ School of Graduate Studies, Management and Science University, Malaysia \\ ${ }^{2}$ International Medical School, Management and Science University, Malaysia \\ Corresponding author: Aishath Niyaf \\ Email: aishaniyaf@yahoo.com
}

\begin{abstract}
Breast cancer $(B C)$, is the most common cancer that affects women, and one of the significant causes of mortality among them. Screening and early detection of the disease are encouraged as a means of reducing mortality and enhancing the prognosis. The purpose of the study is to determine the prevalence of Breast SelfExamination (BSE) uptake and to identify the factors that are associated with the BSE uptake among Maldivian women in the Male' region. The cross-sectional study was carried out over a period of 3 months in the Male' region, of the Maldives. A total of 600 female citizens aged 20-79 years were selected using stratified random sampling method. Data were collected using an interviewer-administered questionnaire. About $82.70 \%, 54.80 \%$, and $63.30 \%$ of the respondents had heard about BC, breast cancer screening (BCS), and BSE respectively. $50.80 \%$ of the respondents had ever performed BSE with only $22.00 \%$ performed it regularly. The significant predictors for BSE uptake were: ever heard about BC [OR=2.069, 95\% CI(1.081-3.959)], ever heard about BSE [OR=2.342, 95\% Cl(1.326-4.137)], ever heard about clinical breast examination (CBE) [OR=1.946, 95\% Cl(1.117-3.390)], knowledge on early detection of $B C[O R=1.077,95 \% \mathrm{Cl}(1.011-1.148)]$, perceptions on the severity of $B C$ $[O R=1.062,95 \% \mathrm{Cl}(1.010-1.116)]$, perceptions on barriers towards $B S E[O R=0.900,95 \% \mathrm{Cl}(0.846-0.958)]$ and selfefficacy [OR=1.112, 95\% Cl(1.076-1.150)]. The findings indicated that there is a pressing need for continued education and behaviour modification intervention programs using theories and models to increase women's overall knowledge and awareness of $B C$ and BCS and modify the long-held incorrect beliefs and misconceptions. In particular, the relevant authorities should play a proactive role in raising awareness of $B C$ and promote BCS.
\end{abstract}

Keywords: Predictors, Breast Cancer, Breast Self-Examination, Maldives

\section{INTRODUCTION}

Breast cancer $(\mathrm{BC})$, is the most common cancer that affects women, and one of the significant causes of mortality among them ${ }^{1}$. The prevalence rate of the disease is projected to rise to 2 million by the year 2030, and most of the incidences are expected to emerge from the developing countries ${ }^{2}$. BC is identified as the second-highest cancer in the Maldives and in females across the population, it is the most common cancer ${ }^{3,4}$.

Early detection of $\mathrm{BC}$ plays a key role in improving prognosis, decreasing morbidity and mortality rates ${ }^{5-7}$. Screening and early detection of the disease are encouraged as a means of reducing mortality and enhancing the prognosis ${ }^{8}$. The most common methods for early detection of BC include Breast SelfExamination (BSE), Clinical Breast Examination (CBE) and Mammography Screening 9. Even though BSE alone may not be adequate for early detection of $B C$, it is considered as an important screening modality in developing countries because it is one of the simplest, non-invasive, and cheap methods to conduct screening for $B C^{10-13}$. Performing regular BSE helps women become more aware of their breast structure and enables them to recognize any abnormal changes in their breasts ${ }^{10,11}$.

Several factors such as sociodemographic characteristics ${ }^{10,14-17}$, women's knowledge on $\mathrm{BC}$, and breast cancer screening (BCS) have shown to be associated with the BSE uptake ${ }^{17}$. 19. Additionally, previous studies based on the Health Belief Model (HBM) provide empirical evidence indicating women's beliefs and perceptions to influence BSE uptake 9, 14, 17, 2023.

The purpose of this study is to determine the prevalence of BSE uptake and to identify the factors that are associated with the BSE uptake among Maldivian women in the Male' region of Maldives. The findings of the study will help all the relevant stakeholders to get an in-depth understanding in relation to the BSE uptake in the country. As BC is the most common cancer among females in the country, the need to implement mechanisms geared towards detecting the condition early and putting forward proper measures to address the problem is exceptionally important. 


\section{METHODOLOGY}

\section{Study Design and Sample}

This cross-sectional study was carried out among a total of 600 female citizens in the Male' Region, Maldives, between December 2019 to February 2020. The stratified random sampling method was used for the selection of the study sample. All six wards of the Male' region were categorised as six stratums. For each of the six strata, census blocks (CB's) were allocated randomly according to the proportion of the population. Next, eleven households from each selected CB were selected, based on simple random sampling, and one eligible woman from the selected households were recruited. The inclusion criteria that were applied for the study were: female citizens aged 20-79 years, comprehend both spoken and written Dhivehi language, no history of $B C$ or any other cancers, mentally fit and consent to participate in the study.

The sample size for this study was estimated by using the following formula:

$$
n=\frac{\left(z_{\alpha}+z_{\beta}\right)^{2}\left(p_{1}\left(1-p_{1}\right)+p_{2}\left(1-p_{2}\right)\right)}{\left(p_{1}-p_{2}\right)^{2}}
$$

$\mathrm{n}=$ sample size estimation

$\mathrm{Z}_{\mathrm{a}}=$ Confidence Level of $95 \%, a$ is 0.05 and the critical value is 1.96

$Z_{B}=$ power of $80 \%, B$ is 0.2 and the critical value is 0.84

$\mathrm{P}_{1}$ and $\mathrm{P}_{2}$ is based on the study conducted by Dahlui et al (2012) where;

$P_{1}=10.4$ (proportion of working women who have had a mammogram ever) and

$P_{2}=16.6$ (proportion of non-working women who have had a mammogram ever).

To address the effect of subject attrition, the sample size was increased by $20 \%$.

The study obtained ethical approval from the ethics committee of Management and Science University, Malaysia and Health Research Committee, Ministry of Health, Maldives.

\section{Instrument}

Data was collected through a validated and reliable interviewer-administered questionnaire which comprised of five sections: 1) Socio-demographic characteristics and family health history of the participants. 2) Sources of BC and BCS information. 3) Participants' knowledge on BC (signs and symptoms, risk factors) and early detection of BC. This section was evaluated through a questionnaire by Parsa et al (2008). Responses were measured using "true", "false" and "I don't know", where respondents were given one point for a correct answer and zero for an incorrect answer or if they do not know. 4) Participants' beliefs on BC and BCS. This section was evaluated by a modified, reliable, and validated tool adapted from Champion's revised health belief model scales (CHBMS) ${ }^{24}$. It comprised of self-reported measures, on the six constructs of the HBM: susceptibility to BC, the seriousness of $B C$, benefits of BSE, barriers to BSE, self-efficacy (confidence), and cues to action (health motivation). All items contained 5 response choices that were measured using a Likert scale ranging from "strongly disagree" (1 point) to "Strongly agree" (5 points). All subscales were positively associated with screening except for the barriers. Construct validity and reliability of the adapted CHBMS were tested by Parsa et al (2008) and found to be acceptable. 5) Participants BSE uptake. This was assessed by self-reported measures on BSE performance, frequency, timing, the reasons for the unwillingness to the uptake as well as the intention for future uptake. The questionnaire was pretested among 60 women and the reliability was confirmed based on Cronbach Alpha values. The Cronbach's alpha values for total knowledge on $B C$ and $B C S$ as well as total beliefs scales (CHBMS) were 0.901 and 0.826 respectively.

\section{Statistical Analysis}

Data analysis was carried out using IBM Statistical Package for Social Sciences (SPSS) version 25. Descriptive and inferential statistical analysis were carried out in the study. Independent t-test and Chi-square tests were performed to determine the factors associated with BSE uptake. Logistic regression analysis was conducted to identify which variables significantly predicted BSE uptake. The level of significance was set at $<0.05$ for all tests.

\section{RESULTS}

Sociodemographic Characteristics, Family Health History and BC and BCS Information

The study respondent's mean age was $39.43 \pm 12.62$ years. Most of them $(75.50 \%)$ were married. About $30.20 \%$ of the respondents attained a secondary school level of education, whereas $33.60 \%$ achieved A' levels and above. More than half of them $(67.50 \%)$ were unemployed while $32.50 \%$ were employed. The mean monthly income and household monthly income was Maldivian Rufiyaa (MVR) $11,213.05 \pm 9663.53$ and $30,064.80 \pm 19,491.62$ respectively ( 1 US $\$=15.42$ MVR). About $11.30 \%$ of the respondents had private health insurance.

A small percentage of respondents indicated ever being diagnosed with a disease or condition(s) related to the breast $(7.70 \%)$ and having a family history of $\mathrm{BC}(6.80 \%)$. About 
$82.70 \%, 54.80 \%$, and $63.30 \%$ of the respondents had heard about BC, BCS, and BSE respectively. The major sources of $B C$ information indicated by the study respondents were the internet and television with $46.20 \%$ and $44.00 \%$ respectively.

\section{BSE Uptake}

About half $(50.80 \%)$, reported ever having performed BSE. Of those who performed, only $22.00 \%$ had done it on a regular monthly basis, while most women reported that they perform BSE sometimes. Regarding when BSE was done, only $28.50 \%$ of women reported they perform BSE 1-2 days after the period had stopped. Taking into contemplation, the number of times BSE was done in the previous year, $51.50 \%, 26.60 \%$, and $22.00 \%$ had performed BSE less than 4 times, 5-8 times, and more than 9 times respectively. The reasons indicated by the study respondents for not doing BSE were: do not have a need for it $(68.80 \%)$, lack of knowledge on BSE $(24.40 \%)$, not knowing how to do it $(20.30 \%)$, being too busy $(5.40 \%)$, forgetting about it $(4.10 \%)$, and takes a long time to do it $(0.30 \%)$. Approximately $61.00 \%$ of the study respondents expressed that they intend to do regular BSE in the future.

\section{Factors Associated with the BSE Uptake} Sociodemographic, Family Health History and $B C$ and $B C S$ Information with BSE Uptake As shown in table 1 and 2 , the variables, age ( $p$-value $=0.002)$, educational level ( $p$ value $<0.001)$, employment status ( $p$ value $=0.003)$, regular medical check-up ( $p$ value $=0.022)$, ever heard about BC ( $p$ value $<0.001)$, ever heard about BCS (pvalue $<0.001)$, ever heard about BSE ( $p$ value $<0.001$ ), ever heard about CBE ( $p$ value $<0.001$ ), ever heard about Mammogram ( $p$-value $<0.001)$, ever had a CBE done ( $p$ value $<0.001$ ), and ever had a Mammogram done $(p$-value $<0.001)$, were statistically significant and found to be associated to influence the BSE uptake. The other sociodemographic and health history variables, which are: monthly income, monthly household income, marital status, insurance status, ever diagnosed for any breast disease/conditions, and family history of BC, depict non-significant $\mathrm{p}$-values indicating that there is no mean difference among the two groups.

\section{Knowledge and Beliefs (CHBMS) on BC and $B C S$ with BSE Uptake}

The relationship and comparison between BSE uptake (those who had performed BSE versus those who had not performed BSE) with knowledge and beliefs (CHBMS) on BC and BCS are unveiled in table 3 . Significant mean difference among the two groups were observed for knowledge on symptoms of $B C(p-$ value $<0.001)$, risk factors of $B C \quad(p$ value<0.001), early detection of $B C$ (pvalue $<0.001$ ), benefits of BSE ( $p$-value $<0.001$ ), barriers to BSE ( $p$-value $<0.001$ ), self-efficacy $(p$-value $<0.001)$, and health motivation ( $p$ value $=0.022$ ). No significant difference between the two groups was found for the susceptibility and the severity sub-scales.

\section{Significant Predictors for BSE Uptake}

Table 4 depicts the logistic regression model for the predictors of BSE uptake. The variables which were found to be associated with the BSE uptake, as well as those based on the HBM theory were included in the regression analysis. The strongest predictor for BSE uptake was having heard about BSE, signifying that women who have heard about BSE were two times more likely to perform BSE than those who have not heard about it $(\mathrm{OR}=2.342$, 95\% Cl:1.326-4.137). Moreover, those women who had heard about $B C(O R=2.069,95 \% \mathrm{Cl}$ : 1.081-3.959) and CBE (OR=1.946, 95\% Cl: 1.117-3.390) were more likely to perform BSE than those who have not heard about it. Furthermore, those who had more insight on early detection of $\mathrm{BC}(\mathrm{OR}=1.077,95 \% \mathrm{Cl}$ : 1.011-1.148) were more likely to perform BSE than those who lack the specific knowledge. In relation to beliefs on BC and BCS variables, those women who have more confidence in their ability to perform screening $(O R=1.112$, $95 \% \mathrm{Cl}: 1.076-1.150)$, those who perceive that $\mathrm{BC}$ is a serious disease, or having the disease would have severe consequences ( $O R=1.062$, 95\% Cl: 1.010-1.116), were more likely to perform BSE than those who lack the confidence and such beliefs. In addition, those who perceive greater barriers to BSE (OR=0.900, 95\% Cl: 0.846-0.958) were less likely to perform BSE than those women who lack the belief. 
Table 1: Association Between Sociodemographic, Family Health History, and BC and BCS Information Variables with BSE Uptake

\begin{tabular}{|c|c|c|c|}
\hline \multirow[t]{2}{*}{ Characteristics } & \multicolumn{3}{|c|}{ Statistics } \\
\hline & BSE done $(n=192)$ & BSE not done $(n=272)$ & \\
\hline & n (\%) & n (\%) & p-value \\
\hline \multicolumn{4}{|l|}{ Marital status } \\
\hline Currently married & $239(52.80)$ & $214(47.20)$ & 0.098 \\
\hline Currently not married & $66(44.90)$ & $81(55.10)$ & \\
\hline \multicolumn{4}{|l|}{ Educational level } \\
\hline Lower level & $168(42.20)$ & $230(57.80)$ & $<0.001^{*}$ \\
\hline Higher level & $137(67.80)$ & $65(32.20)$ & \\
\hline \multicolumn{4}{|l|}{ Employment status } \\
\hline Employed & $116(59.50)$ & $79(40.50)$ & $0.003^{*}$ \\
\hline Unemployed & $189(46.70)$ & $216(53.30)$ & \\
\hline \multicolumn{4}{|c|}{ Insurance status (Private) } \\
\hline Yes & $42(61.80)$ & $26(38.20)$ & 0.056 \\
\hline No & $263(49.40)$ & $269(50.60)$ & \\
\hline \multicolumn{4}{|c|}{ Ever diagnosed for any breast disease } \\
\hline Yes & $27(58.70)$ & $19(41.30)$ & 0.267 \\
\hline No & $278(50.20)$ & $276(49.80)$ & \\
\hline \multicolumn{4}{|l|}{ Family history of $B C$} \\
\hline Yes & $24(58.50)$ & $17(41.50)$ & 0.307 \\
\hline No & $281(50.30)$ & $278(49.70)$ & \\
\hline \multicolumn{4}{|c|}{ Regular medical check-up } \\
\hline Yes & $117(57.40)$ & $87(42.60)$ & $0.022^{*}$ \\
\hline No & $188(47.50)$ & $208(52.50)$ & \\
\hline \multicolumn{4}{|l|}{ Ever heard about $B C$} \\
\hline Yes & $283(57.10)$ & $213(42.90)$ & $<0.001^{*}$ \\
\hline No & $22(21.20)$ & $82(78.80)$ & \\
\hline \multicolumn{4}{|l|}{ Ever heard about BCS } \\
\hline Yes & $219(66.60)$ & $110(33.40)$ & $<0.001^{*}$ \\
\hline No & $86(31.70)$ & $185(68.30)$ & \\
\hline \multicolumn{4}{|l|}{ Ever heard about BSE } \\
\hline Yes & $258(67.90)$ & $122(32.10)$ & $<0.001^{*}$ \\
\hline No & $47(21.40)$ & $173(78.60)$ & \\
\hline \multicolumn{4}{|l|}{ Ever heard about CBE } \\
\hline Yes & $197(72.70)$ & $74(27.30)$ & $<0.001^{*}$ \\
\hline No & $108(32.80)$ & $221(67.20)$ & \\
\hline \multicolumn{4}{|c|}{ Ever heard about Mammogram } \\
\hline Yes & $172(66.40)$ & $87(33.60)$ & $<0.001^{*}$ \\
\hline No & $133(39.00)$ & $208(61.00)$ & \\
\hline \multicolumn{4}{|l|}{ Ever had a CBE } \\
\hline Yes & $127(66.10)$ & $65(33.90)$ & $<0.001^{*}$ \\
\hline No & $108(39.70)$ & $164(60.30)$ & \\
\hline \multicolumn{4}{|l|}{ Ever had a Mammogram } \\
\hline Yes & $51(57.30)$ & $38(42.70)$ & $<0.001^{*}$ \\
\hline No & $57(33.50)$ & $113(66.50)$ & \\
\hline
\end{tabular}


Table 2: Association Between Sociodemographic, Family Health History, and BC and BCS Information Variables with BSE Uptake

Table 3: Knowledge and Beliefs (CHBMS) on BC and BCS Between Those Who Performed BSE and Those Who Had Not Performed BSE

\begin{tabular}{|c|c|c|c|}
\hline \multicolumn{4}{|l|}{ Variables } \\
\hline & BSE done $(n=305)$ & BSE not done $(n=295)$ & \\
\hline & Mean \pm SD & Mean \pm SD & p-value \\
\hline \multicolumn{4}{|l|}{ Knowledge } \\
\hline Symptoms of BC & $5.22 \pm 2.07$ & $3.74 \pm 2.26$ & $<0.001^{*}$ \\
\hline Risk factors of $B C$ & $6.79 \pm 2.44$ & $5.30 \pm 2.83$ & $<0.001^{*}$ \\
\hline Early detection of $B C$ & $12.85 \pm 3.31$ & $10.13 \pm 4.66$ & $<0.001^{*}$ \\
\hline Total knowledge & $24.86 \pm 5.88$ & $19.17 \pm 8.13$ & $<0.001$ \\
\hline \multicolumn{4}{|l|}{ Beliefs (CHBMS) } \\
\hline Susceptibility to BC & $12.67 \pm 3.31$ & $13.00 \pm 3.37$ & 0.234 \\
\hline Severity of $B C$ & $23.35 \pm 4.40$ & $23.25 \pm 4.52$ & 0.783 \\
\hline Benefits of BSE & $24.26 \pm 2.88$ & $23.27 \pm 3.18$ & $<0.001^{*}$ \\
\hline Barriers towards BSE & $14.48 \pm 3.21$ & $16.65 \pm 3.92$ & $<0.001^{*}$ \\
\hline Self-efficacy (Confidence) & $38.44 \pm 6.31$ & $32.00 \pm 7.33$ & $<0.001^{*}$ \\
\hline Cues to Action (Health motivation) & $22.94 \pm 2.87$ & $22.42 \pm 2.71$ & $0.022^{*}$ \\
\hline Total beliefs & $201.93 \pm 14.33$ & $196.80 \pm 16.76$ & $<0.001$ \\
\hline
\end{tabular}

Bold*: Significance at level $p$-value $<0.05$

\section{DISCUSSION}

The findings of this study indicate low regular BSE uptake rates among Maldivian women. More than half $(63.30 \%)$ of the respondents had heard about BSE. However, only $22.00 \%$ of them performed it regularly. Similar to the present study findings, regular performance of BSE were reported as $21.10 \%$ among Saudi women ${ }^{22}, 18.00 \%$ among university students in Saudi ${ }^{13}, 24.60 \%$ among university students in Iran ${ }^{17}, 26.00 \%$ among undergraduate students in Malaysia ${ }^{10}, 18.60 \%$ among women in Turkey ${ }^{25}, 25.00 \%$ among undergraduate students in Nigeria ${ }^{26}, 20.00 \%$ among rural women in India 27 and $25.50 \%$ among female health personnel in Kathmandu ${ }^{11}$. In contrast, better regular performance of BSE rates than the present study were reported in studies, with $41.40 \%$ among women in Delhi, India ${ }^{28}, 62.80 \%$ among women in Malaysia ${ }^{29}, 37.10 \%$ among university students in Malaysia ${ }^{30}, 47.90 \%$ among women in Sri Lanka ${ }^{31}, 41.50 \%$ female academicians in Turkey ${ }^{32}, 42.90 \%$ among health professionals in Turkey 20 and $39.00 \%$ among women in Taiwan ${ }^{33}$. Nevertheless, these studies too indicate the need for the improvement of BSE uptake.

This study determined statistically significant associations between the variables: age, education level, employment status, regular medical check-ups, ever heard about BC, ever heard about BCS, ever heard about BSE, ever heard about CBE, ever heard about mammography screening, ever had a CBE done and ever had a Mammogram done with BSE uptake. These findings are in line with previous studies $15-17,25,27$ that also found a statistically significant association with educational level and BSE uptake. Likewise, studies have also found the variables age 10,15, 16, 27, 32 and ever heard about BSE ${ }^{34}$ to be associated with BSE uptake. Additionally, parallel to our findings, 
previous studies $17,25,32$ found no significant relationship between family history of $B C$ and BSE uptake. Contrary to our findings, however, some studies found family history of BC $26,27,35$, ${ }^{36}$, marital status $10,16,34,37$ and trained by a doctor to do BSE 10 to have significant associations with the BSE performance.

In the present study, a significant association was found between women's knowledge on BC and BCS with BSE uptake. This finding agrees with the previous studies $17,22,26,27,34,36,38$. Concerning the women's beliefs on BC and
BCS, a significant difference was observed in this study for the subdimensions: benefits of BSE, barriers to BSE, self-efficacy, and health motivation. Comparable to our findings, other studies have also found significant associations between perceived benefits of BSE 17, 20-23, 25, 39, perceived barriers to BSE 20, 22, 25, 34, selfefficacy $17,20,21,23,25,34,39$ and health motivation $20,22,25,34$ with BSE uptake. However, in contrast to our findings, some studies also observed statistically significant associations between the severity of $B C 17,20$ and susceptibility of BC ${ }^{20}$ with BSE uptake.

Table 4: Logistic Regression Analysis for Predicting Likelihood of BSE Uptake

\begin{tabular}{|c|c|c|c|c|c|c|}
\hline Variables & B & S.E. & Wald & $p$-value & OR & $95 \% \mathrm{Cl}$ \\
\hline \multicolumn{7}{|l|}{$\begin{array}{l}\text { Socio-demographic, health history, } \\
\text { and BC and BCS information }\end{array}$} \\
\hline Age & -0.017 & 0.011 & 2.362 & 0.124 & 0.984 & $0.963-1.005$ \\
\hline Educational level & 0.453 & 0.261 & 3.019 & 0.082 & 1.573 & $0.944-2.621$ \\
\hline Employment status & -0.026 & 0.246 & 0.011 & 0.915 & 0.974 & $0.602-1.577$ \\
\hline Regular medical check-up & 0.172 & 0.243 & 0.499 & 0.480 & 1.188 & $0.737-1.914$ \\
\hline Ever heard about BC & 0.727 & 0.331 & 4.824 & $0.028^{*}$ & 2.069 & $1.081-3.959$ \\
\hline Ever heard about BCS & -0.197 & 0.291 & 0.458 & 0.498 & 0.821 & $0.465-1.452$ \\
\hline Ever heard about BSE & 0.851 & 0.290 & 8.598 & $0.003^{*}$ & 2.342 & $1.326-4.137$ \\
\hline Ever heard about CBE & 0.666 & 0.283 & 5.526 & $0.019^{*}$ & 1.946 & $1.117-3.390$ \\
\hline $\begin{array}{l}\text { Ever heard about mammography } \\
\text { screening }\end{array}$ & -0.223 & 0.257 & 0.756 & 0.385 & 0.800 & $0.484-1.323$ \\
\hline \multicolumn{7}{|l|}{ Knowledge on $\mathrm{BC}$ and $\mathrm{BCS}$} \\
\hline Symptoms of BC & 0.072 & 0.055 & 1.760 & 0.185 & 1.075 & $0.966-1.196$ \\
\hline Risk factors of $B C$ & 0.014 & 0.048 & 0.079 & 0.778 & 1.014 & $0.922-1.115$ \\
\hline Early detection of $B C$ & 0.074 & 0.032 & 5.247 & $0.022^{*}$ & 1.077 & $1.011-1.148$ \\
\hline \multicolumn{7}{|l|}{ Beliefs on BC and BCS (CHBMS) } \\
\hline Susceptibility to BC & -0.027 & 0.033 & 0.665 & 0.415 & 0.973 & $0.912-1.039$ \\
\hline Severity of $B C$ & 0.060 & 0.025 & 5.513 & $0.019 *$ & 1.062 & $1.010-1.116$ \\
\hline Benefits of BSE & 0.005 & 0.039 & 0.018 & 0.893 & 1.005 & $0.932-1.085$ \\
\hline Barriers towards BSE & -0.105 & 0.032 & 10.945 & $0.001^{*}$ & 0.900 & $0.846-0.958$ \\
\hline Self-efficacy (Confidence) & 0.106 & 0.017 & 39.567 & $<0.001^{*}$ & 1.112 & $1.076-1.150$ \\
\hline Cues to Action (Health motivation) & -0.024 & 0.041 & 0.347 & 0.556 & 0.976 & $0.900-1.058$ \\
\hline
\end{tabular}

Chi-square for Omnibus test is 252.955, with significance level of $<0.001, d f=18$, Nagelkerke $R^{2}=0.459$,

Cox \& Snell $R^{2}=0.344$. The Chi-square value for the Hosmer-Lemeshow Goodness of Fit test is 7.201, with a significance level of 0.515 . Bold*: Significance at level $p$-value $<0.05$.

The regression model indicated that as women's awareness and knowledge on BC and early detection of $B C$ increased, so did their performance of BSE. In addition, as HBM suggests, BSE uptake levels were increased with the increase in women's perceptions that $B C$ is a serious disease with severe consequences, as well as with the increase in women's confidence to perform BSE. Moreover, when women perceive fewer barriers in relation to the required preventive action, their BSE performance increased. This finding is also in agreement with findings of previous studies ${ }^{10}, 17,22,26,30,34,40,41$ that found the participant's knowledge on BCS as a significant predictor for BSE uptake. In the same way, perceived self-efficacy ${ }^{15}, 17,21-23,32$,
34,38 , perceived severity of $B C{ }^{17}$, perceived barriers 15, 22, 23, 34, 38 and having heard about BSE ${ }^{34,42}$ was found as significant predictors for BSE uptake in previous studies. However, previous studies also determined age 15, educational level 17 , married 34,40 , attending CBE ${ }^{40}$, employed ${ }^{22}$, family history of $B C{ }^{22,} 26$, 30 , susceptibility to $B C{ }^{32}$, health motivation ${ }^{32}$, ${ }^{34}$, benefits of BSE ${ }^{17,21,32}$ and skills taught by a doctor 10 as significant predictors for BSE uptake.

Nevertheless, there were some limitations to this study. Firstly, the study findings could not be generalized to all Maldivian women, as it was limited only to the population of the Male' region. Secondly, the BSE uptake was based on 
self-reported responses, which may lead to overestimation or underestimation of the screening uptake.

\section{CONCLUSIONS}

Early detection of $\mathrm{BC}$ is crucial to reduce the morbidity and mortality from the disease. This study determined significant predictors for BSE uptake among Maldivian women in the Male' region. The findings indicated that there is a pressing need for continued education and behaviour modification intervention programs using theories and models to increase women's overall knowledge and awareness of $B C$ and BCS and to modify the long-held incorrect cultural beliefs and misconceptions. In particular, the relevant authorities should play a proactive role in raising awareness of $B C$ and BCS. Multiple effective strategies are needed for the management of the disease and to promote regular screening among Maldivian women.

\section{Acknowledgements}

The authors would kindly like to acknowledge and thank all women who participated in the study and all those who kindly assisted and supported in conducting the research.

\section{Competing interests}

The authors declare no conflict of interest in this work.

\section{Funding}

This study was self-funded.

\section{Authors' contributions}

All authors read and approved the final manuscript.

\section{REFERENCES}

1. Momenimovahed $\mathrm{Z}$, Salehiniya $\mathrm{H}$. Epidemiological characteristics of and risk factors for breast cancer in the world. Breast Cancer (Dove Med Press). 2019;11:151-64.

2. Gupta A, Shridhar K, Dhillon PK. A review of breast cancer awareness among women in India: Cancer literate or awareness deficit? European Journal of Cancer. 2015;51(14):2058-66.

3. WHO. Cancer Country Profiles. 2014.

4. GLOBOCAN. Maldives, Cancer statistics. 2018.

5. Subramanian $P$, Oranye NO, Masri AM, Taib NA, Ahmad N. Breast cancer knowledge and screening behaviour among women with a positive family history: a cross sectional study. Asian Pacific journal of cancer prevention : APJCP. 2013;14(11):6783-90.

6. Todd A, Stuifbergen A. Breast Cancer Screening Barriers and Disability. Rehabilitation nursing : the official journal of the Association of Rehabilitation Nurses. 2012;37(2):749.

7. WHO. Breast cancer: Prevention and control 2019. Available from: https: / / www.who.int/cancer/detecti on/breastcancer/en/index 1. html.

8. Ghoncheh M, MohammadianHafshejani A, Salehiniya H. Incidence and Mortality of Breast Cancer and their Relationship to Development in Asia2015. 6081-7 p.

9. Yilmaz $\mathrm{D}$, Bebis $\mathrm{H}$, Ortabag $\mathrm{T}$. Determining the awareness of and compliance with breast cancer screening among Turkish residential women. Asian Pacific journal of cancer prevention : APJCP. 2013;14(5):32818.

10. Akhtari-Zavare M, Latiff LA, Juni MH, Said SM, Ismail IZ. Knowledge of Female Undergraduate Students on Breast Cancer and Breast Selfexamination in Klang Valley, Malaysia. Asian Pacific journal of cancer prevention : APJCP. 2015;16(15):62315.

11. Shrestha Pradhan S, Shrestha, R., Parajuli, P., Khagi, R., \& Bhandari, B. - Knowledge, Attitude and Practice Regarding Breast Self Examination Among Female Health Personnel. Journal of Kathmandu Medical College. Journal of Kathmandu Medical College. 2018;Vol. 6, No. 4(22):156-60.

12. RamBihariLal Shrivastava S, Saurabh Shrivastava P, Ramasamy J. Self Breast Examination: A Tool for Early Diagnosis of Breast Cancer2013. 135-9 p.

13. Alomair AN, Felemban DG, Felemban MS, Awadain JA, Altowairqi AS, Alfawzan NF, et al. Knowledge, attitude, and practice of breast selfexamination toward breast cancer among female students at King Saud University in Riyadh, Saudi Arabia. International Journal of Medicine in 
Developing Countries. 2020;4(2):42934.

14. Kirag N, Kızılkaya M. Application of the Champion Health Belief Model to determine beliefs and behaviors of Turkish women academicians regarding breast cancer screening: $A$ cross sectional descriptive study. BMC women's health. 2019;19(1):132.

15. Farzaneh E, Heydari $H$, Shekarchi AA, Kamran A. Breast and cervical cancerscreening uptake among females in Ardabil, northwest Iran: a communitybased study. OncoTargets and therapy. 2017;10:985-92.

16. Malik R, Vera N, Dayal C, Choudhari A, Mudaliar J, Noovao Hill A, et al. Factors associated with breast cancer awareness and breast self-examination in Fiji and Kashmir India - a crosssectional study. BMC Cancer. 2020;20(1):1078.

17. Didarloo A, Nabilou B, Khalkhali HR. Psychosocial predictors of breast selfexamination behavior among female students: an application of the health belief model using logistic regression. BMC Public Health. 2017;17(1):861.

18. Donnelly TT, Khater AH, Al-Bader SB, Al Kuwari MG, Malik M, Al-Meer N, et al. Factors that influence awareness of breast cancer screening among Arab women in Qatar: results from a cross sectional survey. Asian Pacific journal of cancer prevention : APJCP. 2014;15(23):10157-64.

19. Parsa P, Kandiah M, Parsa N. Factors associated with breast selfexamination among Malaysian women teachers. Eastern Mediterranean health journal $=$ La revue de sante de la Mediterranee orientale = al-Majallah al-sihhiyah li-sharq al-mutawassit. 2011;17(6):509-16.

20. Yılmaz M, Durmuş T. Health Beliefs and Breast Cancer Screening Behavior among a Group of Female Health Professionals in Turkey. The Journal of Breast Health. 2016;12(1):18-24.

21. Darvishpour A, Vajari SM, Noroozi S. Can Health Belief Model Predict Breast Cancer Screening Behaviors? Open access Macedonian journal of medical sciences. 2018;6(5):949-53.
22. Abolfotouh MA, BaniMustafa AA, Mahfouz AA, Al-Assiri MH, Al-Juhani AF, Alaskar AS. Using the health belief model to predict breast self examination among Saudi women. BMC Public Health. 2015;15:1163.

23. Fouladi N, Pourfarzi F, Mazaheri E, Asl HA, Rezaie M, Amani F, et al. Beliefs and behaviors of breast cancer screening in women referring to health care centers in northwest Iran according to the champion health belief model scale. Asian Pacific journal of cancer prevention : APJCP. 2013;14(11):6857-62.

24. Parsa $P$, Kandiah $M$, Mohd Nasir MT, Hejar AR, Nor Afiah MZ. Reliability and validity of Champion's Health Belief Model Scale for breast cancer screening among Malaysian women. Singapore medical journal. 2008;49(11):897-903.

25. Ertem G, Dönmez YC, Dolgun E. Determination of the Health Belief and Attitude of Women Regarding Breast Cancer and Breast Self-Exam. J Breast Health. 2017;13(2):62-6.

26. Ossai E, Azuogu B, Ogaranya I, Ogenyi $A$, Enemor D, Nwafor M. Predictors of practice of breast self-examination: A study among female undergraduates of Ebonyi State University, Abakaliki, Nigeria. Nigerian Journal of Clinical Practice. 2019;22(3):361-9.

27. Veena KS, Kollipaka R, Rekha R. The Knowledge and attitude of breast self examination and mammography among rural women. International Journal of Reproduction, Contraception, Obstetrics and Gynecology. 2015;4(5):1511-6.

28. Dahiya N, Basu S, Singh MC, Garg S, Kumar R, Kohli C. Knowledge and Practices Related to Screening for Breast Cancer among Women in Delhi, India. Asian Pacific journal of cancer prevention : APJCP. 2018;19(1):155-9.

29. Nik Farid ND, Abdul Aziz N, Al-Sadat N, Jamaludin M, Dahlui M. Clinical Breast Examination As the Recommended Breast Cancer Screening Modality in a Rural Community in Malaysia; What Are the Factors That Could Enhance Its Uptake? PloS one. 2014;9(9):e106469. 
30. Hassan MR, Ghazi HF, AS M, Jasmin SJ. Knowledge and practice of breast selfexamination among female nonmedical students in Universiti Kebangasaan Malaysia (UKM) in Bangi. Malaysian Journal of Public Health Medicine. 2017;17(1):51-8.

31. Nilaweera RI, Perera S, Paranagama N, Anushyanthan AS. Knowledge and practices on breast and cervical cancer screening methods among female health care workers: a Sri Lankan experience. Asian Pacific journal of cancer prevention : APJCP. 2012;13(4):1193-6.

32. Kirag N, Kızılkaya M. Application of the Champion Health Belief Model to determine beliefs and behaviors of Turkish women academicians regarding breast cancer screening: A cross sectional descriptive study. BMC women's health. 2019;19(1):132.

33. Wu TY, Chung S, Yeh MC, Chang SC, Hsieh HF, Ha SJ. Understanding breast cancer screening practices in Taiwan: a country with universal health care. Asian Pacific journal of cancer prevention : APJCP. 2012;13(9):428994.

34. Mekuria M, Nigusse A, Tadele A. Breast Self-Examination Practice and Associated Factors Among Secondary School Female Teachers in Gammo Gofa Zone, Southern, Ethiopia. Breast Cancer (Dove Med Press). 2020;12:110.

35. Al-Naggar RA, Bobryshev YV. Practice and barriers of mammography among Malaysian women in the general population. Asian Pacific journal of cancer prevention : APJCP. 2012;13(8):3595-600.

36. Getu MA, Kassaw MW, Tlaye KG, Gebrekiristos AF. Assessment of breast self-examination practice and its associated factors among female undergraduate students in Addis Ababa University, Addis Ababa, Ethiopia, 2016. Breast Cancer (Dove Med Press). 2018;11:21-8.

37. Akhtari-Zavare M, Ghanbari-Baghestan A, Latiff LA, Matinnia N, Hoseini M. Knowledge of breast cancer and breast self-examination practice among Iranian women in Hamedan, Iran. Asian
Pacific journal of cancer prevention : APJCP. 2014;15(16):6531-4.

38. Guilford K, McKinley E, Turner L. Breast Cancer Knowledge, Beliefs, and Screening Behaviors of College Women: Application of the Health Belief Model. American Journal of Health Education. 2017;48(4):256-63.

39. Shiryazdi SM, Kholasehzadeh G, Neamatzadeh $\mathrm{H}$, Kargar S. Health Beliefs and Breast Cancer Screening Behaviors among Iranian Female Health Workers. Asian Pacific Journal of Cancer Prevention. 2014;15:981722.

40. Dahlui M, Gan DE, Taib NA, Pritam R, Lim J. Predictors of breast cancer screening uptake: a pre intervention community survey in Malaysia. Asian Pacific journal of cancer prevention : APJCP. 2012;13(7):3443-9.

41. Rakkapao N, Promthet S, Moore MA, Solikhah S, Hurst C. Assessing Breast Cancer Awareness in Thai Women: Validation of the Breast Cancer Awareness Scale (B-CAS). Asian Pacific journal of cancer prevention : APJCP. 2017;18(4):995-1005.

42. Albeshan SM, Hossain SZ, Mackey MG, Naser Osmani SS, Brennan PC. Understanding better the knowledge, beliefs, and attitudes toward breast cancer and breast screening practices among women living in Ras Al Khaimah, United Arab Emirates (UAE). Proceedings of the 3rd International Conference on Public Health. 2017; 3(2):208-22. 